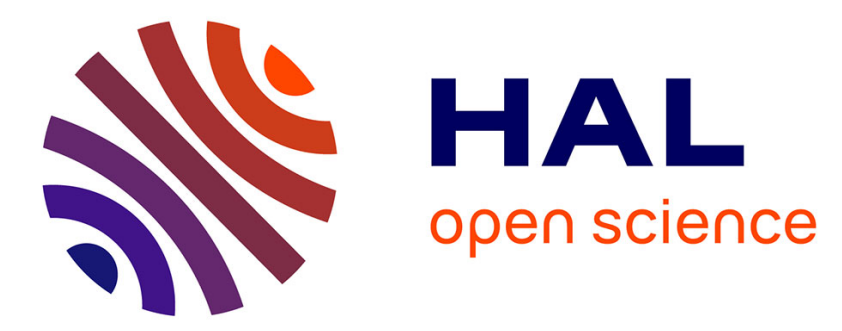

\title{
Fatty acid isoprenoid alcohol ester synthesis in fruits of the African Oil Palm (Elaeis guineensis)
}

Philipp Gutbrod, Sophie Reichert, Katharina Gutbrod, Amazigh Hamai, Claire Bréhélin, Georges Ngando-Ebongue, Peter Dörmann

\section{- To cite this version:}

Philipp Gutbrod, Sophie Reichert, Katharina Gutbrod, Amazigh Hamai, Claire Bréhélin, et al.. Fatty acid isoprenoid alcohol ester synthesis in fruits of the African Oil Palm (Elaeis guineensis). Phytochemistry, 2021, 185, pp.112684. hal-03141513

\author{
HAL Id: hal-03141513 \\ https://hal.science/hal-03141513
}

Submitted on 15 Feb 2021

HAL is a multi-disciplinary open access archive for the deposit and dissemination of scientific research documents, whether they are published or not. The documents may come from teaching and research institutions in France or abroad, or from public or private research centers.
L'archive ouverte pluridisciplinaire HAL, est destinée au dépôt et à la diffusion de documents scientifiques de niveau recherche, publiés ou non, émanant des établissements d'enseignement et de recherche français ou étrangers, des laboratoires publics ou privés. 
Fatty acid isoprenoid alcohol ester synthesis in fruits of the African Oil Palm (Elaeis guineensis) $^{1}$

Philipp Gutbrod $^{a}$, Sophie Reichert ${ }^{a}$, Katharina Gutbrod ${ }^{a}$, Amazigh Hamai $^{b}$, Claire Bréhélin ${ }^{b}$, Georges Ngando-Ebongue ${ }^{c}$, Peter Dörmannª*

a Institute of Molecular Physiology and Biotechnology of Plants (IMBIO), University of Bonn, Karlrobert-Kreiten-Strasse 13, 53115 Bonn, Germany

b Université de Bordeaux, CNRS, Laboratoire de Biogenèse Membranaire, UMR 5200, F33140 Villenave d'Ornon, France

${ }^{c}$ Institute of Agricultural Research for Development, Center for Oil Palm Research (IRADCEREPAH) of La Dibamba, P.O. Box 243, Douala, Cameroon

${ }^{*}$ Corresponding author.

E-mail address: doermann@uni-bonn.de, phone +49-228-732830, fax +49-228-73-1696 (P. Dörmann)

${ }^{1}$ This manuscript is dedicated to Vincent Arondel (Université de Bordeaux, CNRS, Laboratoire de Biogenèse Membranaire) without whom this work would not have been possible and who unfortunately passed away in June 2018. 


\section{ABSTRACT}

The African Oil Palm (Elaeis guineensis; family Arecaceae) represents the most important oil crop for food and feed production and for biotechnological applications. Two types of oil can be extracted from palm fruits, the mesocarp oil which is rich in palmitic acid and in carotenoids (provitamin A) and tocochromanols (vitamin E), and the kernel oil with high amounts of lauric and myristic acid. We identified fatty acid phytyl esters (FAPEs) in the mesocarp and kernel tissues of mature fruits, mostly esterified with oleic acid and very long chain fatty acids. In addition, fatty acid geranylgeranyl esters (FAGGEs) accumulated in mesocarp and kernels to even larger amounts. In contrast, FAPEs and FAGGEs amounts and fatty acid composition in leaves were very similar. Analysis of wild accessions of African Oil Palm from Cameroon revealed a considerable variation in the amounts and composition of FAPEs and FAGGEs in mesocarp and kernel tissues. Exogenous supplementation of phytol or geranylgeraniol to mesocarp slices resulted in the incorporation of these alcohols into FAPEs and FAGGEs, respectively, indicating that they are synthesized via enzymatic reactions. Three candidate genes of the esterase/lipase/thioesterase (ELT) family were identified in the Oil Palm genome. The genes are differentially expressed in mesocarp tissue with EgELT1 showing the highest expression. Geranylgeraniol from FAGGE might be recycled and used as a substrate for the synthesis of carotenoids and tocotrienols during fruit development. Thus, FAPEs and FAGGEs in the mesocarp and kernel of Oil Palm provide an additional metabolic source for fatty acids and phytol or geranylgeraniol, respectively.

Keywords: Elaeis guineensis; Arecaceae; African Oil Palm; mass spectrometry analysis; fatty acid phytyl ester; fatty acid geranylgeranyl ester; esterase/lipase/thioesterase-like acyltransferases 


\section{Introduction}

The fruits of the African Oil Palm (Elaeis guineensis Jacq.; family Arecaceae) are a major source of edible oil (triacylglycerol) accounting for more than a third of the total world vegetable oil production (Woittiez et al., 2017). Two different oils can be obtained from the fruits, the mesocarp provides the orange to red colored crude palm oil, whereas the kernel oil is obtained from the seed. The major fatty acids of the crude palm oil are palmitic acid (16:0; number of carbon atoms:number of double bonds), oleic acid (18:1 $\left.{ }^{\Delta 9 c i s}\right)$, and linoleic acid (18:2 $\left.{ }^{\Delta 9,12 \text { cis }}\right)$. The fatty acid composition of mesocarp oil varies considerably depending on the genotype and the environment, with amounts of $0-2 \%$ (14:0), 32-52\% (16:0), 3-8\% (18:0), 35-50\% (18:1) and 5-13\% (18:2) (Bafor and Osagie, 1986; Montoya et al., 2014; Oo et al., 1986; Sambanthamurthi, 2000; Xiao et al., 2019). In contrast, the most abundant fatty acid of the kernel oil is lauric acid (12:0), accounting for $30-54 \%$ of total fatty acids, followed by oleic acid $\left(18: 1^{\Delta 9 c i s}\right)$ and myristic acid (14:0) which account for $9-20 \%$ and $14-18 \%$, respectively, and smaller amounts of 10:0 (2-6\%), 16:0 (7-11\%), 18:0 (1-4\%) and 18:2 (2-3\%) (Akpanabiatu et al., 2001; Crombie, 1956; Kok et al., 2011; Lieb et al., 2017).

In addition to triacylglycerol, crude palm oil contains lipid-soluble vitamins including tocochromanols (vitamin E) and carotenoids (provitamin A) (Sambanthamurthi, 2000). Tocochromanols and carotenoids are derived from the isoprenoid biosynthesis pathway in the plastid (Gutbrod et al., 2019). Geranylgeranyl-diphosphate, an activated C20 isoprenoid alcohol harboring 4 double bonds, is the precursor for the tocotrienol group of vitamin $\mathrm{E}$ (Fig. 1). The condensation of two geranylgeranyl-diphosphate moieties results in the synthesis of phytoene, a C40 isoprenoid, which is the precursor for $\alpha$-carotene and $\beta$-carotene. Previous studies indicated that geranylgeranyl-diphosphate is employed for the synthesis of geranylgeranyl-chlorophyll by chlorophyll synthase (Gutbrod et al., 2019). The reduction of 3 of the 4 double bonds in geranylgeranyl-chlorophyll by geranylgeranyl reductase (GGR) leads to the synthesis of (phytyl-) chlorophyll. Chlorophyll degradation results in the release of phytol which can be converted into the activated form of phytyl-diphosphate by two subsequent kinases, VTE5 and VTE6 (Valentin et al., 2006; vom Dorp et al., 2015). Phytyl-diphosphate 
gives rise to the hydrophobic tail for tocopherol synthesis. Therefore, different enzymes compete for a common geranylgeranyl-diphosphate precursor thus limiting the synthesis of the different isoprenoids (Camagna et al., 2019; Fray et al., 1995).

Dephosphorylation of the isoprenoid alcohol-diphosphates in chloroplasts can result in the release of the free alcohols, geranylgeraniol and phytol (Nualkaew et al., 2005). Free geranylgeraniol and free phytol can be esterified with activated fatty acids resulting in the production of fatty acid geranylgeranyl esters (FAGGE) or fatty acid phytyl esters (FAPE), respectively (Nagel et al., 2014). In Arabidopsis, FAPEs are synthesized by chloroplastic PHYTYL ESTER SYNTHASE1 and PHYTYL ESTER SYNTHASE2 (PES1/ELT1, PES2/ELT1) using phytol derived from chlorophyll breakdown (Lippold et al., 2012). PES1 and PES2 belong to the plant ELT (esterase/lipase/thioesterase) family of proteins that contain hydrolase and acyltransferase domains. Different FAPE molecular species including phytol-12:0, phytol-16:0 and phytol-16:3 accumulate in Arabidopsis leaves (Lippold et al., 2012). The tomato PYP1 protein, a close homolog of Arabidopsis PES1 and PES2, is involved in the synthesis of xanthophyll esters in petals (Ariizumi et al., 2014). FAPEs serve as a transient sink for phytol derived from chlorophyll degradation (Lippold et al., 2012), while FAGGEs store geranylgeraniol and might play a role in plant defense against pathogens (Nagel et al., 2014).

FAPEs and FAGGEs were previously detected in different plant oils (Biedermann et al., 2008), while their accumulation in the African Oil Palm mesocarp or kernel remained unclear. Therefore, a mass spectrometry based method was employed to determine the FAPE and FAGGE contents and composition in the mesocarp and kernel of Oil Palm fruits. In addition, the FAPE and FAGGE contents and composition were assessed in different wild accessions to determine their natural variation in Oil Palm. Finally, the pathways of isoprenoid alcohol ester synthesis in Oil Palm were studied by supplying phytol or geranylgeraniol to mesocarp slices and by identifying candidate isoprenoid ester synthase genes.

\section{Results}




\subsection{Tissue specific accumulation of fatty acid isoprenoid alcohol esters in Oil Palm fruits and}

leaves

We first quantified the FAPE and FAGGE contents in mesocarp and kernels of the Deli $x$ La Mé line (Fig. 2a) which is an important commercial variety widely grown in different areas of the world. The total amounts of FAPEs and FAGGEs in mesocarp are higher compared with kernel tissue. Total FAPEs and FAGGEs amount to $\sim 0.001$ and $\sim 0.01 \%$ of mesocarp oil of the line Deli x La Mé, respectively, based on an oil content of $60.8 \pm 1.4 \%$ (total extractable oil; mean $\pm S D, n=3$ ). Furthermore, the amounts of FAGGEs are higher compared with FAPE in each tissue. The molecular species composition of FAPEs and FAGGEs is presented in Fig. $2 b$ and c. The FAPEs in mesocarp contain mostly 20:1, 26:0, 24:0, 18:1, and 22:0 acyl groups, while kernel FAPEs are rich in 20:1, 18:1, 22:0, 26:0, 18:2 and18:0. The FAGGEs of the mesocarp contain mostly 18:1, 24:0, 18:2, 22:0, 20:0 acyl groups. FAGGEs of the kernel are enriched with medium chain acyl groups (12:0, 14:0), monounsaturated fatty acids (18:1, $20: 1)$ and long chain saturated fatty acids (18:0, 20:0, 22:0, 24:0).

For comparison, the FAPE and FAGGE amounts and composition were measured in green leaves of Oil Palm. Figure 3 shows that the contents of FAPE and FAGGE in green leaves are very similar, and the fatty acid composition of the two ester types was also highly related, with mostly very long chain saturated fatty acids of $20-26$ carbon atoms. Furthermore, FAPE and FAGGE both contained considerable amounts of odd chain acyl groups (C21, C23, C25).

\subsection{Natural variation of FAPE and FAGGE contents and composition in Oil Palm fruits}

Next we assessed the total FAPE and FAGGE contents in mesocarp and kernel tissues of seven different wild accessions of Oil Palm, in comparison with the Deli x La Mé line. The fruits of the wild accessions were derived from trees grown at the Institute of Agricultural Research for Development, Center for Oil Palm Research (IRAD-CEREPAH) in Dibamba, Cameroon. These plants originated from seeds collected from wild trees growing at different locations in 
Cameroon (Table 1). Total FAPE and FAGGE contents were calculated based on dry weight of the mesocarp or kernel tissues. The calculation of the data per fresh weight resulted in lower numbers, but the differences between the lines were still visible, indicating that they were independent of the water content. The mesocarp of the accessions from Widikum, Batie and Moulondou contained lower amounts of total FAPEs compared with Deli x La Mé. Furthermore, the accessions Widikum and Bafut showed higher FAGGE contents while Batie and Bengbis contained lower total FAGGE contents as compared to the Deli x La Mé line (Fig. 4a, b). The composition of FAPEs and FAGGEs in mesocarp is presented in Fig. 4c, d. Significant differences in FAPE and FAGGE contents were found for several lines, in particular for esters containing $16: 3$ or very long chain saturated fatty acids (20:0 and longer).

The amounts of FAPEs or FAGGEs in kernels of the different wild accessions were very similar (Fig. 5a, b). Only Batie and Kola kernels showed significantly different total FAGGE contents as they were lower compared to Deli $x$ La Mé. The differences in fatty acid composition of FAPEs and FAGGEs between the kernels of wild accessions were also minor. Some lines showed significant differences in the amounts of esters with short chain fatty acids $(8: 0,10: 0)$ or very long chain saturated fatty acids $(20: 0,24: 0,26: 0)(F i g, 5 c, d)$.

\subsection{Exogenous isoprenoid alcohols are used for isoprenoid alcohol ester synthesis in} mesocarp

To elucidate whether FAPEs and FAGGEs are synthesized by enzyme-dependent reactions, phytol and geranylgeraniol were supplied to mesocarp slices. Subsequently, FAPEs and FAGGEs were extracted and quantified. As a negative control, enzyme activities in mesocarp slices were inactivated by heat prior to incubation with isoprenoid alcohols. Incubation with phytol or geranylgeraniol resulted in the accumulation of FAPE or FAGGE in mesocarp slices, respectively, while ester synthesis in heat-inactivated slices was abolished (Fig. 6). Therefore, FAPE and FAGGE synthesis in mesocarp depends on enzyme activities. The supplementation of phytol to mesocarp slices resulted in a 18-fold increase in total FAPE content compared to the control $\left(0.045 \pm 0.003\right.$ vs. $\left.0.816 \pm 0.081 \mathrm{nmol} \mathrm{mg}^{-1} \mathrm{FW}\right)$, mostly due to the increase in 
phytol-18:1, phytol-18:2, phytol-16:0, phytol-18:3 and phytol-14:0 (Fig. 6a). In addition, FAGGEs were increased by 1.7 fold $\left(0.115 \pm 0.008\right.$ vs. $\left.0.198 \pm 0.015 \mathrm{nmol} \mathrm{mg}{ }^{-1} \mathrm{FW}\right)$ when geranylgeraniol was supplied to mesocarp (Fig. 6b), but this was less pronounced than for FAPEs. FAGGEs containing 18:1 showed the most prominent increase, while FAGGEs containing very long chain fatty acids including 20:0, 22:0 and 24:0 showed a moderate increase.

\subsection{Candidate enzymes involved in FAPE and FAGGE biosynthesis in Oil Palm}

The finding that the esterification of phytol and geranylgeraniol with fatty acids can be inactivated by heat, indicated that specific acyltransferases are involved in their synthesis. In Arabidopsis, esterification of phytol is catalyzed by AtPES1/AtELT1 and AtPES2/AtELT2, members of the ELT acyltransferase family. Orthologous sequences were searched in the published Oil Palm genome by BLAST using the Arabidopsis protein sequences of AtELT1 to AtELT6 as queries. Three candidate sequences (EgELT1, EgELT2, EgELT3) were found that contained a putative chloroplast transit signal, a hydrolase and acyltransferase domain, in analogy with the AtELT sequences from Arabidopsis. In addition, we retrieved the orthologous sequences to AtELT1-6 from one additional dicot plant (tomato, Solanum lycopersicum L.) and from three additional monocot plants (barley, Hordeum vulgare L.; rice, Oryza sativa L.; corn, Zea mays L.). Phylogenetic analysis indicated that the sequences fall into two clusters, one containing EgELT1 and EgELT2 together with AtPES1 from Arabidopsis, SIPYP1 from tomato, and sequences from barley, rice and corn, and a second cluster with EgELT3, AtPES2 and the other Arabidopsis ELT sequences, and the remaining tomato, barley, rice and corn sequences (Fig. 7a).

The transcript abundance of the three EgELT sequences in different fruit tissues was studied by qPCR. All three genes are expressed in mature mesocarp tissue, with EgELT1 being expressed 15 to 20 times higher than the other two sequences (Fig. 7b). 


\section{Discussion}

3.1. Tissue-specific accumulation of molecular species of FAPE and FAGGE in Oil Palm fruits and leaves

The molecular species composition of FAPEs and FAGGEs in mesocarp is different from each other and different from the fatty acid composition of mesocarp oil (mostly 16:0, 18:1, 18:2) because very long chain acyl groups accumulate in FAPEs (20:1) and FAGGEs (24:0) which are very low in mesocarp oil (Fig. 2b, c) (Bafor and Osagie, 1986; Biedermann et al., 2008). The FAPE composition in kernels is similar to the respective composition in mesocarp. In contrast to FAGGEs, FAPEs in kernels contain only low amounts of medium chain fatty acids $(12: 0,14: 0)$ which are absent from the mesocarp oil, but are present in kernel oil (Crombie, 1956). The reason for the differences in acyl composition between FAPE and FAGGEs, and between the ester fraction and the fatty acid composition of the mesocarp or kernel oils, remains unclear.

Interestingly, we detected both FAPEs and FAGGEs in leaves of Oil Palm trees. The amounts of FAPE were comparable to those of FAGGEs, in contrast to mesocarp and kernel tissue, where FAGGEs were much more abundant. This finding reflects the fact that leaves contain large amounts of chlorophyll which gives rise to phytol released after hydrolysis. Furthermore, we found mostly very long-chain saturated fatty acids in leaf FAPEs and FAGGEs, with even and odd numbers of carbon atoms (C20 - C26).

FAPEs and FAGGEs are presumably synthesized in the plastids (Lippold et al., 2012) while oil production is localized to the ER. Furthermore, fatty acid de novo synthesis in the plastids is limited to chain lengths of 16 or 18 carbon atoms, while very long chain fatty acids of 20 or more carbon atoms are produced by elongation at the ER. Lipid trafficking between the ER and the chloroplast involves an ATP binding cassette transporter (ABC) and possibly additional transport systems at contact sites between the chloroplast envelope and the ER (Hurlock et al., 2014; Michaud and Jouhet, 2019). Therefore, it is possible that very long chain 
fatty acids derived from the ER might be transferred back to plastids where they can be incorporated into phytyl esters or geranylgeranyl esters.

The finding that the levels of FAGGEs are higher than those of FAPEs in mesocarp and kernel suggests that the metabolism of geranylgeraniol plays a larger role than that of phytol, in line with the fact that tocotrienols which are derived from geranylgeraniol, are more abundant compared with phytol-derived tocopherols (Sambanthamurthi, 2000). During early stages of development, the mesocarp of Oil Palm fruits contains chlorophyll which is presumably involved in photosynthesis and is degraded during fruit ripening (Sambanthamurthi, 2000). In Arabidopsis leaves, FAPEs accumulate in response to chlorophyll degradation (Lippold et al., 2012) which is stimulated during chlorosis, leaf senescence or seed ripening, and which results in the release of phytol. Therefore, FAPEs in mesocarp might become a sink for phytol that in its free form is toxic to the cells. Interestingly, non-photosynthetic tissues like corn seeds also contain low amounts of chlorophyll presumably involved in tocopherol production (Diepenbrock et al., 017).

Previous reports showed that FAGGEs are involved in defense responses against insect herbivors (Nagel et al., 2014). Fruits of Oil Palm are generally dispersed by large animals that feed on them. Thus, the presence of FAGGEs in the mesocarp might help to prevent insect herbivory that might result in tissue damage and create entry ports for microbial pathogens. Since the kernel is additionally protected by a rigid shell, the need for anti-herbivory compounds presumably is less pronounced as compared to the mesocarp.

Free phytol released from chlorophyll or from FAPEs can be phosphorylated two times yielding phytyl-diphosphate that serves as a substrate for tocopherol synthesis (vom Dorp et al., 2015). It is likely that free geranylgeraniol can also be phosphorylated yielding geranylgeraniol-diphosphate. Therefore, FAGGEs might form a transient storage pool for geranylgeraniol that can be converted into geranylgeranyl-diphosphate for the synthesis of tocotrienols, carotenoids or isoprenoid-derived phytohormones. This storage function might be important in kernels during germination for the stimulation of early development of the Oil Palm seedling. 


\subsection{Natural variation of FAPE and FAGGE contents in African Oil Palm fruits}

The variation in total amounts of FAPE and FAGGE in the kernel was low as compared to the mesocarp where the contents of FAPE and FAGGE varied by a factor of two compared to the control line Deli $x$ La Mé. It has been shown that the variation for a given trait in a population is maximal for the population where the highest genetic variation is expected, that is usually the place of its origin (Singh et al., 2020). Indeed, Oil Palms have been used by humans for several thousand years in the region of its origin in West Africa, but commercial cultivation of elite lines started in East Asia only about 100 years ago (Sambanthamurthi, 2000). Therefore, high trait variation was expected and indeed, we found strong variation in FAPE and FAGGE contents in the wild accessions.

\subsection{Exogenously supplied isoprenoid alcohols are used for fatty acid isoprenoid alcohol ester} synthesis in mesocarp

In Arabidopsis, FAPE synthesis is catalyzed by acyltransferases of the ELT family, and ELTlike enzymes have been suggested to catalyze FAGGE biosynthesis as well (Lippold et al., 2012; Nagel et al., 2014). Therefore, EgELT enzymes of Oil Palm might be involved in the synthesis of FAPE and FAGGE (Fig. 1). Interestingly, the FAPE amount increases 20-fold, whereas the FAGGE content only doubles after feeding phytol or geranylgeraniol, respectively (Fig. 6). This could be explained by a higher substrate specificity of the EgELT enzymes for phytol as compared to geranylgeraniol. However, the higher accumulation of FAGGEs compared with FAPEs in mesocarp might suggest that the mesocarp contains higher amounts of geranylgeraniol than phytol. Therefore, the high accumulation of FAGGEs in Oil Palm mesocarp might be explained by the higher availability of geranylgeraniol rather than the substrate specificity of EgELT enzymes.

\subsection{Candidate enzymes involved in FAPE and FAGGE biosynthesis in Oil Palm}


Of the three candidate genes (EgELT1, EgELT2, EgELT3) in Oil Palm with sequence similarity to AtPES1/AtELT1 and AtPES2/AtELT2, EgELT1 shows highest expression in mature mesocarp suggesting that it represents the major phytyl/geranylgeranyl ester synthase in this tissue. The generation of the phylogenetic tree showed that the ELT sequences from different plants cluster in two branches, each cluster containing related sequences from Arabidopsis, Oil Palm, tomato, barley, rice and corn. Therefore, the sequences could not be separated according to their origin from monocot or dicot plants, suggesting that there is no monocotspecific group of ELT sequences distinct from dicot sequences. This finding argues against the scenario that a monocot-specific group of ELTs shows specificity for FAGGE production, while dicot ELTs might rather be involved in FAPE production. Thus, the high accumulation of FAGGEs in mesocarp and kernel might be caused by the relative substrate availability of phytol versus geranylgeraniol. The determination of the substrate specificity of the EgELT enzymes from Oil Palm might shed more light on their specific function.

Recently, a gene with sequence similarity to the acyltransferase part of Arabidopsis AtPES1/AtPES2 was isolated from the cyanobacterium Synechocystis. The Synechocystis acyltransferase possesses phytyl ester synthesis and diacylglycerol acyltransferase activity (Aizouq et al., 2020). The finding that the Synechocystis acyltransferase is capable of FAPE synthesis suggests that the acyltransferase domain of plant ELT enzymes is sufficient for FAPE synthesis.

\section{Experimental}

\subsection{General Experimental Procedures}

Fatty acid isoprenoid esters were analyzed by direct infusion mass spectrometry on a quadrupole time of flight (Q-TOF) mass spectrometer (Agilent 6530 Accurate Mass) (Lippold et al., 2012; vom Dorp et al., 2015). Phytol and geranylgeraniol were obtained from Chemimpex (Wood Dale, IL, USA) and (Carbosynth Copmton, UK), respectively. The margaric acid phytyl ester (phytol-17:0) was synthesized from margaric acid and phytol according to (Gellerman et al., 1975). 


\subsection{Plant material and sample preparation}

Seeds were collected from wild trees of the African Oil Palm (Elaeis guineensis Jacq.; family Arecaceae) growing at different sites in Cameroon during two fruit collection campaigns in 2008. The accessions were germinated, raised at the nursery and field planted in 2011 at the Research Center of La Dibamba (Institute of Agricultural Research for Development, Center for Oil Palm Research, IRAD-CEREPAH). For the experiments, fruits of the wild trees and of the commercial Deli x La Mé line were harvested in 2017. All fruits were harvested from palms of the same age and grown under the same conditions. Fruits were generally harvested from ripe bunches (i.e. bunches with 1-5 fallen fruits) and were flash frozen and stored at $-80^{\circ} \mathrm{C}$. The exocarp was pealed from a single frozen fruit without thawing. The pealed mesocarp was dissected under liquid nitrogen and ground to a fine powder in a precooled mortar. The mesocarp powder was transferred into pre-cooled microfuge tubes without thawing. The shell of the kernel was cracked to expose the kernel. The endosperm of the kernel was dissected, ground to a fine powder as described above, and the endosperm powder was transferred to a microfuge tube without thawing. The mesocarp and endosperm powders were stored at $-80^{\circ} \mathrm{C}$. Leaves of the African Oil Palm (Elaeis guineensis Jacq.) were obtained from a tree growing in the greenhouse of the Botanical Gardens of the University of Bonn in 2020. The leaves were frozen in liquid nitrogen, lyophilized and used for lipid extraction.

\subsection{Isolation and quantification of fatty acid isoprenoid alcohol esters}

For the extraction of FAPEs and FAGGEs, $50 \mathrm{mg}$ of the frozen mesocarp or endosperm powders were transferred to a precooled microfuge tube without thawing. Diethyl ether $(1 \mathrm{~mL})$ and $1 \mathrm{nmol}$ of the internal standard phytol-17:0 were added. After vortexing, $500 \mu \mathrm{L}$ of $300 \mathrm{mM}$ ammonium acetate were added, the sample was vortexed again and centrifuged (5000 x g, 5 min). The upper phase was transferred to a glass vial and the extraction was repeated two more times. The solvent of the combined extracts was evaporated under a flow of nitrogen gas. The lipids were dissolved in $1 \mathrm{~mL}$ of hexane and the wax ester fraction containing FAPEs 
and FAGGEs was purified by solid-phase extraction (SPE). A silica column (500 mg) was equilibrated with hexane and the sample was loaded on the column. After washing the column with hexane, wax esters were eluted with hexane/diethylether $(99: 1, \mathrm{v} / \mathrm{v})$. The solvent was evaporated with a nitrogen stream. Fatty acid isoprenoid alcohol esters were dissolved in chloroform/methanol/300 mM ammonium acetate (300:665:35, v/v/v) and analyzed by Q-TOF MS/MS as previously described (Lippold et al., 2012; vom Dorp et al., 2015).

\subsection{Isoprenoid alcohol feeding to mesocarp slices}

One frozen fruit of Deli x La Mé was pealed and the mesocarp cut into thin slices. About 50 $\mathrm{mg}$ of slices were placed in $2 \mathrm{~mL}$ microfuge tubes. After addition of $500 \mu \mathrm{L}$ of deionized water, the slices were thawed at room temperature for $15 \mathrm{~min}$. One sample was incubated at $95^{\circ} \mathrm{C}$ for $15 \mathrm{~min}$ ('heat-inactivated control'). The water was removed and the slices were incubated in $500 \mu \mathrm{L}$ of MES/Tergitol buffer (2-(N-morpholino)ethanesulfonic acid- $\mathrm{KOH}, \mathrm{pH} 6.8,0.045 \%$ (v/v) Tergitol). For isoprenoid alcohol feeding, $0.1 \%(\mathrm{v} / \mathrm{v})$ phytol or geranylgeraniol were added. The samples were incubated in the dark with shaking for $48 \mathrm{~h}$. The buffer was removed, the mesocarp slices were washed three times in MES/Tergitol buffer and frozen in liquid nitrogen. Ceramic beads were added and the mesocarp ground to a fine powder with $2 \times 6000$ strokes, 15 s each, in a Precellys homogenizer (Bertin Instruments). Extraction and SPE purification of isoprenoid alcohol esters were performed as described above.

\subsection{Identification and sequence analysis of ELT genes from Oil Palm}

Arabidopsis PES1, PES2, ELT3, ELT4, ELT5 and ELT6 amino acid sequences were used for tblastn searches against the published genome sequences of African Oil Palm (Elaeis guineensis), tomato (Solanum lycopersicum L.), rice (Oryza sativa L.), barley (Hordeum vulgare L.) and. at the National Center for Biotechnological Information (https://blast.ncbi.nlm.nih.gov/Blast.cgi). The domain structures of the protein sequences were analyzed using pfam (pfam.xfam.org), and plastid transit peptides were predicted using TargetP-2.0 (http://www.cbs.dtu.dk/services/TargetP/). Sequences were aligned using 
ClustalW, and phylogenetic trees were constructed based on the neighbor-joining method with the bootstrap test with 1000 repetitions using MEGA7 (Kumar et al., 2016).

\subsection{RNA extraction, $c D N A$ synthesis and $q P C R$}

Total RNA was extracted from 200 mg mesocarp powder according to Meisel et al. (Meisel et al., 2005). Residual DNA was digested with the TURBO Dnase Kit (Invitrogen). cDNA was synthesized using random hexamer primers and the Revertaid 1st cDNA Synthesis Kit (Life Technologies). qPCR was performed in a total volume of $20 \mu \mathrm{L}$ using My-Budget $5 \times$ Eva Green (R) QPCR-Mix II (Rox) (Biobudget) and $450 \mathrm{nM}$ of each primer. The relative transcript abundance was quantified according to the Comparative Ct method (Schmittgen and Livak, 2008) using two reference genes (cyclophilin and GRAS transcription factor). The oligonucleotide primers used for qPCR were EgELT1, LOC105032120 (forward, reverse; GCT AGG GAG AAA GTA GCC CG, GCA TGG TCA TGC TAT GTT TCA A); EgELT2, LOC105032118 (AGC AAA GTT TCC GGT CAA CG, AGC ACA ACC ATG TGC AAG AAC); EgELT3, LOC105033840 (TGA ATG GCT GAG TTG GGG TC, TGG CGA TAA GGT GAG AGG GA); cyclophilin (CTC GTC TGA TGT CGT CTA, CTG CTG GTA CTC TGG TAA); GRAS transcription factor (CGG AAG AGT CAC ATC AAT CG, GGA GCA AGA AGC CAA CAC). The lowest expressing transcript of the three genes (EgELT3) was used as calibrator sample.

\section{Declaration of competing interest}

The authors declare that they have no known competing financial interests or personal relationships that could have appeared to influence the work reported in this paper.

\section{Acknowledgements}

We thank Sylvie Lissandreau and Karim Ait-Alouache (Université de Bordeaux) for funding management. We are grateful to Josef Manner from Botanical Garden of the University of Bonn for providing leaf material of African Oil Palm. 


\section{Funding}

This work is part of the VITAPALM project of the Long term EU-Africa research and innovation Partnership on food and nutrition security and sustainable Agriculture (LEAPAgri). The project was supported by the Federal Ministry of Food and Agriculture (BMEL; grant number 2817LEAP05) and by the Agence Nationale de la Recherche (ANR), France. This project has received funding from the European Union's Horizon 2020 research and innovation programme under grant number 727715 . 


\section{References}

Aizouq, M., Peisker, H., Gutbrod, K., Melzer, M., Hölzl, G., Dörmann, P., 2020. Triacylglycerol and phytyl ester synthesis in Synechocystis sp. PCC6803. Proc. Natl. Acad. Sci. USA 117 (11), 62166222. https://doi.org/10.1073/pnas.1915930117.

Akpanabiatu, M.I., Ekpa, O.D., Mauro, A., Rizzo, R., 2001. Nutrient composition of Nigerian palm kernel from the dura and tenera varieties of the oil palm (Elaeis guineensis). Food Chem. 72 (2), 173-177. https://doi.org/10.1016/S0308-8146(00)00215-6.

Ariizumi, T., Kishimoto, S., Kakami, R., Maoka, T., Hirakawa, H., Suzuki, Y., Ozeki, Y., Shirasawa, K., Bernillon, S., Okabe, Y., Moing, A., Asamizu, E., Rothan, C., Ohmiya, A., Ezura, H., 2014. Identification of the carotenoid modifying gene PALE YELLOW PETAL 1 as an essential factor in xanthophyll esterification and yellow flower pigmentation in tomato (Solanum lycopersicum). Plant J. 79 (3), 453-465. https://doi.org/10.1111/tpj.12570.

Bafor, M.E., Osagie, A.U., 1986. Changes in lipid class and fatty acid composition during maturation of mesocarp of oil palm (Elaeis guineensis) variety dura. J. Sci. Food Agric. 37 (9), 825-832. https://doi.org/10.1002/jsfa.2740370902.

Biedermann, M., Haase-Aschoff, P., Grob, K., 2008. Wax ester fraction of edible oils: Analysis by online LC-GC-MS and GC×GC-FID. Eur. J. Lipid Sci. Technol. 110 (12), 1084-1094. https://doi.org/10.1002/ejlt.200800090.

Camagna, M., Grundmann, A., Bär, C., Koschmieder, J., Beyer, P., Welsch, R., 2019. Enzyme fusion removes competition for geranylgeranyl diphosphate in carotenogenesis. Plant Physiol. 179 (3), 1013-1027. https://doi.org/10.1104/pp.18.01026.

Crombie, W.M., 1956. Fat metabolism in the West African Oil Palm (Elaeis guineensis). J. Exp. Bot. 7 (2), 181-193. https://doi.org/10.1093/jxb/7.2.181.

Diepenbrock, C.H., Kandianis, C.B., Lipka, A.E., Magallanes-Lundback, M., Vaillancourt, B., GóngoraCastillo, E., Wallace, J.G., Cepela, J., Mesberg, A., Bradbury, P.J., Ilut, D.C., Mateos-Hernandez, M., Hamilton, J., Owens, B.F., Tiede, T., Buckler, E.S., Rocheford, T., Buell, C.R., Gore, M.A., DellaPenna, D., 2017. Novel loci underlie natural variation in vitamin $E$ levels in maize grain. Plant Cell 29 (10), 2374-2392. https://doi.org/10.1105/tpc.17.00475.

Fray, R.G., Wallace, A., Fraser, P.D., Valero, D., Hedden, P., Bramley, P.M., Grierson, D., 1995. Constitutive expression of a fruit phytoene synthase gene in transgenic tomatoes causes dwarfism by redirecting metabolites from the gibberellin pathway. Plant J. 8 (5), 693-701. https://doi.org/10.1046/j.1365-313X.1995.08050693.x.

Gellerman, J., Anderson, W., Schlenk, H., 1975. Synthesis and analysis of phytyl and phytenoyl wax esters. Lipids 10 (11), 656-661.

Gutbrod, K., Romer, J., Dörmann, P., 2019. Phytol metabolism in plants. Prog. Lipid Res. 74, 1-17. https://doi.org/10.1016/j.plipres.2019.01.002.

Hurlock, A.K., Roston, R.L., Wang, K., Benning, C., 2014. Lipid trafficking in plant cells. Traffic 15 (9), 915-932. https://doi.org/10.1111/tra.12187.

Kok, S., Ong-Abdullah, M., Ee, G.C., Namasivayam, P., 2011. Comparison of nutrient composition in kernel of tenera and clonal materials of oil palm (Elaeis guineensis Jacq.). Food Chem. 129 (4), 1343-1347. https://doi.org/10.1016/j.foodchem.2011.05.023.

Kumar, S., Stecher, G., Tamura, K., 2016. MEGA7: Molecular evolutionary genetics analysis version 7.0 for bigger datasets. Mol. Biol. Evolut. 33 (7), 1870-1874. https://doi.org/10.1093/molbev/msw054.

Lieb, V.M., Kerfers, M.R., Kronmüller, A., Esquivel, P., Alvarado, A., Jiménez, V.M., Schmarr, H.-G., Carle, R., Schweiggert, R.M., Steingass, C.B., 2017. Characterization of mesocarp and kernel lipids from Elaeis guineensis Jacq., Elaeis oleifera Kunth Cortés, and their interspecific hybrids. J. Agricult. Food Chem. 65 (18), 3617-3626. https://doi.org/10.1021/acs.jafc.7b00604. 
Lippold, F., vom Dorp, K., Abraham, M., Hölzl, G., Wewer, V., Lindberg Yilmaz, J., Lager, I., Montandon, C., Besagni, C., Kessler, F., Stymne, S., Dörmann, P., 2012. Fatty acid phytyl ester synthesis in chloroplasts of Arabidopsis. Plant Cell 24 (5), 2001-2014.

Meisel, L., Fonseca, B., González, S., Baeza-Yates, R., Cambiazo, V., Campos, R., Gonźalez, M., Orellana, A., Retamales, J., Silva, H., 2005. A rapid and efficient method for purifying high quality total RNA from peaches (Prunus persica) for functional genomics analyses. Biol. Res. 38 (1), 8388. https://doi.org/10.4067/s0716-97602005000100010.

Michaud, M., Jouhet, J., 2019. Lipid trafficking at membrane contact sites during plant development and stress response. Front. Plant Sci. 10, 2. https://doi.org/10.3389/fpls.2019.00002.

Montoya, C., Cochard, B., Flori, A., Cros, D., Lopes, R., Cuellar, T., Espeout, S., Syaputra, I., Villeneuve, P., Pina, M., Ritter, E., Leroy, T., Billotte, N., 2014. Genetic architecture of palm oil fatty acid composition in cultivated oil palm (Elaeis guineensis Jacq.) compared to its wild relative $E$. oleifera (H.B.K) Cortés. PLoS One 9 (5), e95412. https://doi.org/10.1371/journal.pone.0095412.

Nagel, R., Berasategui, A., Paetz, C., Gershenzon, J., Schmidt, A., 2014. Overexpression of an isoprenyl diphosphate synthase in spruce leads to unexpected terpene diversion products that function in plant defense. Plant Physiol. 164 (2), 555-569. https://doi.org/10.1104/pp.113.228940.

Nualkaew, N., De-Eknamkul, W., Kutchan, T.M., Zenk, M.H., 2005. Geranylgeraniol formation in Croton stellatopilosus proceeds via successive monodephosphorylations of geranylgeranyl diphosphate. Tetrahedron Lett. 46 (50), 8727-8731. https://doi.org/10.1016/j.tetlet.2005.10.048.

Oo, K.-c., Lee, K.-B., Ong, A.S.H., 1986. Changes in fatty acid composition of the lipid classes in developing oil palm mesocarp. Phytochemistry 25 (2), 405-407. https://doi.org/10.1016/S00319422(00)85489-8.

Sambanthamurthi, R., 2000. Chemistry and biochemistry of palm oil. Prog. Lipid Res. 39 (6), 507-558. https://doi.org/10.1016/s0163-7827(00)00015-1.

Schmittgen, T.D., Livak, K.J., 2008. Analyzing real-time PCR data by the comparative $C_{T}$ method. Nat. Protoc. 3 (6), 1101-1108. https://doi.org/10.1038/nprot.2008.73.

Singh, R., Low, E.-T.L., Ooi, L.C.-L., Ong-Abdullah, M., Ting, N.-C., Nookiah, R., Ithnin, M., Marjuni, M., Mustaffa, S., Yaakub, Z., Amiruddin, M.D., Manaf, M.A.A., Chan, K.-L., Halim, M.A.A., Sanusi, N.S.N.M., Lakey, N., Sachdeva, M., Bacher, B., Garner, P.A., MacDonald, J.D., Smith, S.W., Wischmeyer, C., Budiman, M.A., Beil, M., Stroff, C., Reed, J., van Brunt, A., Berg, H., Ordway, J.M., Sambanthamurthi, R., 2020. Variation for heterodimerization and nuclear localization among known and novel oil palm SHELL alleles. New Phytol. 226 (2), 426-440. https://doi.org/10.1111/nph.16387.

Valentin, H.E., Lincoln, K., Moshiri, F., Jensen, P.K., Qi, Q., Venkatesh, T.V., Karunanandaa, B., Baszis, S.R., Norris, S.R., Savidge, B., Gruys, K.J., Last, R.L., 2006. The Arabidopsis vitamin E pathway gene -1 mutant reveals a critical role for phytol kinase in seed tocopherol biosynthesis. Plant Cell 18 (1), 212-224.

vom Dorp, K., Hölzl, G., Plohmann, C., Eisenhut, M., Abraham, M., Weber, A.P.M., Hanson, A.D., Dörmann, P., 2015. Remobilization of phytol from chlorophyll degradation is essential for tocopherol synthesis and growth of Arabidopsis. Plant Cell 27 (10), 2846-2859. https://doi.org/10.1105/tpc.15.00395.

Woittiez, L.S., van Wijk, M.T., Slingerland, M., van Noordwijk, M., Giller, K.E., 2017. Yield gaps in oil palm: A quantitative review of contributing factors. Eur. J. Agron. 83, 57-77. https://doi.org/10.1016/j.eja.2016.11.002.

Xiao, Y., Xia, W., Mason, A.S., Cao, Z., Fan, H., Zhang, B., Zhang, J., Ma, Z., Peng, M., Huang, D., 2019. Genetic control of fatty acid composition in coconut (Cocos nucifera), African oil palm (Elaeis 
guineensis), and date palm (Phoenix dactylifera). Planta 249 (2), 333-350.

https://doi.org/10.1007/s00425-018-3003-x.

\section{Figure Legends}

Fig. 1. Schematic overview of isoprenoid alcohol metabolism in African Oil Palm.

Geranygeranyl-diphosphate (geranylgeranyl-PP) can be esterified with chlorophyllide yielding geranylgeranyl-chlorophyll, or dephosphorylated to yield geranylgeraniol.

Geranylgeranyl-chlorophyll is reduced to phytol-containing chlorophyll by geranylgeranyl reductase (GGR), and the resulting phytol tail can be released. Isoprenoid alcohols can be esterified with fatty acids producing FAPE and FAGGE, respectively, presumably by one of the EgELT enzymes in Oil Palm. Geranylgeranyl-PP is the substrate for the synthesis of carotenoids and tocotrienol. Phytol can be phosphorylated two times by VTE5 and VTE6 yielding phytyl-diphosphate (phytol-PP), the precursor for tocopherol synthesis.

Fig. 2. Fatty acid isoprenoid alcohol ester content and composition in mesocarp and kernel of the Deli x La Mé line. The wax ester fraction was isolated from mesocarp and kernel tissues of fruits of the Deli x La Mé line by solid phase extraction. Fatty acid phytyl esters (FAPEs) and fatty acid geranylgeranyl esters (FAGGEs) were quantified by Q-TOF MS/MS analysis. (a) Total FAPE and FAGGE contents in mesocarp and kernel tissues. (b) Molecular species composition of FAPEs and FAGGEs in mesocarp and kernel tissue. Data show mean $\pm S D, n=3$. Values significantly different between tissues, or between FAPE and FAGGE in the same tissue, are indicated by asterisks. ${ }^{*}, \mathrm{P}<0.05 ;{ }^{* *}, \mathrm{P}<0.01$; Student's $t$ test.

Fig. 3. Fatty acid isoprenoid alchohol ester content in leaves of African Oil Palm. The wax ester fraction was isolated from green leaves by solid phase extractions. Fatty acid phytyl esters (FAPEs) and fatty acid geranylgeranyl esters (FAGGEs) were quantified by Q-TOF MS/MS analysis. Data show mean $\pm S D, n=3$. 
Fig. 4. Fatty acid isoprenoid alcohol ester contents and composition in the mesocarp of wild accessions of the African Oil Palm. The wax ester fraction was isolated from mesocarp of the Deli x La Mé line and of wild accessions by solid phase extraction. FAPEs and FAGGEs were quantified by Q-TOF MS/MS analysis. (a) Total FAPE contents; (b) total FAGGE contents; (c) FAPE composition; (d) FAGGE composition. Data are mean and SD, $n=3$. Values significantly different from Deli $x$ La Mé; ${ }^{*} P<0.05$; ${ }^{* *} P<0.01$; Student's $t$ test.

Fig. 5. Fatty acid FAPE and FAGGE contents and composition in kernels of wild accessions of the African Oil Palm. The wax ester fraction was isolated from kernel tissue of the Deli $x$ La Mé line and of wild accessions by solid phase extraction. FAPEs and FAGGEs were quantified by Q-TOF MS/MS analysis. (a) Total FAPE contents; (b) total and FAGGE contents; (c) FAPE composition; (d) FAGGE composition. Data are mean and SD, $\mathrm{n}=3$. Values significantly different from Deli $x$ La Mé; ${ }^{*} P<0.05$; ${ }^{* *} \mathrm{P}<0.01$; Student's $t$ test.

Fig. 6. Incorporation of exogenous isoprenoid alcohols into fatty acid alcohol esters in mesocarp of African Oil Palm fruits. Mesocarp slices were incubated in buffer containing phytol or geranylgeraniol, and the wax ester fraction was isolated by solid phase extraction. FAPEs and FAGGEs were quantified by Q-TOF MS/MS analysis. Enzyme activities were inactivated by heat in control slices. (a) FAPE composition in mesocarp after phytol feeding compared to heat-inactivated control. (b) FAGGE composition in mesocarp after geranylgeraniol feeding compared to heat-inactivated control. Data are mean and SD, $\mathrm{n}=3$. Values significantly different from the heat inactivated control; ${ }^{*} \mathrm{P}<0.05$; ${ }^{* *} \mathrm{P}<0.01$; Student's $t$ test.

Fig. 7. Phylogeny and expression analysis of ELT-like proteins of African Oil Palm. (a) The phylogenetic tree was constructed using the Neighbor-Joining method with the bootstrap test with 1000 repetitions (MEGA X software). (b) Transcript abundance was analyzed in 
mesocarp tissue by qPCR and are shown relative to the expression of EgELT3 (set to 1.0). Data are mean and $S D, n=3$. Values significantly different from expression of LOC105032120; *P < 0.05; Student's $t$ test. AtPES1/ELT1, Arabidopsis thaliana At1g54570; AtPES2/ELT2, At3g26840; AtELT3, At3g26820; AtELT4, At5g41120; AtELT5, At5g41130; AtELT6,At3g02030; SIPYP1, Solanum lycopersicum Solyc01g098110; SIPYP1 homologue, Solyc02g094430; EgELT1, Elaeis guineensis LOC105032120, XP019701740.1; EgELT2, LOC105032118, XP01904773.1; EgELT3, LOC105033840, XP029117244.1, XP010907079.1.

Graphical Abstract

The oil from mesocarp of African Oil Palm contains different fatty acid esters of geranylgeraniol or phytol.

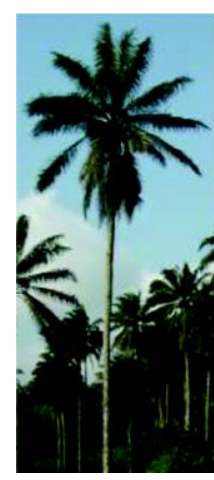

\section{African Oil Palm} (Elaeis guineensis Jacq.)

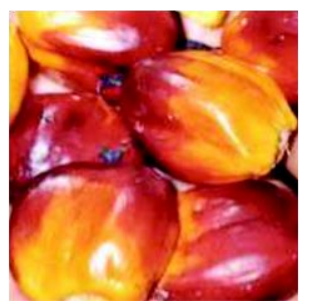

Fatty Acid Phytyl Ester

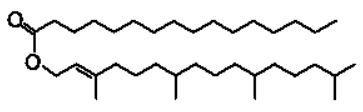

Fatty Acid Geranylgeranyl Ester

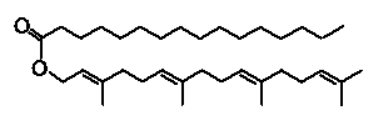


Table 1: African Oil Palm Lines used in this study

\begin{tabular}{|l|l|l|c|c|c|c|c|c|}
\hline Line & $\begin{array}{l}\text { Type of } \\
\text { line }\end{array}$ & \multicolumn{1}{|c|}{ Origin } & $\begin{array}{c}\text { Latitude } \\
(\mathrm{N})\end{array}$ & $\begin{array}{c}\text { Longitude } \\
(\mathrm{E})\end{array}$ & $\begin{array}{c}\text { Altitude } \\
(\mathrm{m})\end{array}$ & $\begin{array}{c}\text { Fruit } \\
\text { form }\end{array}$ & $\begin{array}{c}\text { Mesocarp } \\
\text { RWC }(\%)\end{array}$ & $\begin{array}{c}\text { Kernel } \\
\text { RWC (\%) }\end{array}$ \\
\hline Deli x La Mé & $\begin{array}{l}\text { Elite } \\
\text { hybrid }\end{array}$ & La Dibamba & 0350.154 & 0946.350 & 47 & Tenera & $31.8 \pm 3.7$ & $21.8 \pm 2.9$ \\
\hline Widikum & Wild & Northwest & 0552.489 & 0945.654 & 595 & Dura & $33.5 \pm 4.1$ & $19.3 \pm 4.2$ \\
\hline Bengbis & Wild & South & 0323.00 & 1218.00 & 624 & Dura & $41.4 \pm 3.3$ & $24.4 \pm 3.3$ \\
\hline Kola & Wild & Littoral & 0448.168 & 0946.171 & 434 & Tenera & $29.9 \pm 2.5$ & $23.0 \pm 2.4$ \\
\hline Bafut & Wild & Northwest & 0601.833 & 1012.202 & 1092 & Dura & $43.0 \pm 3.3$ & $24.0 \pm 3.3$ \\
\hline Kribi & Wild & South & 0250.736 & 0953.161 & 9 & Dura & $35.3 \pm 3.8$ & $21.8 \pm 3.8$ \\
\hline Batie & Wild & West & 0517.554 & 1015.838 & 1170 & Dura & $29.7 \pm 3.3$ & $20.5 \pm 2.5$ \\
\hline Mouloundoun & Wild & East & 0202.567 & 1512.503 & 275 & Dura & $34.0 \pm 3.3$ & $22.2 \pm 2.1$ \\
\hline
\end{tabular}




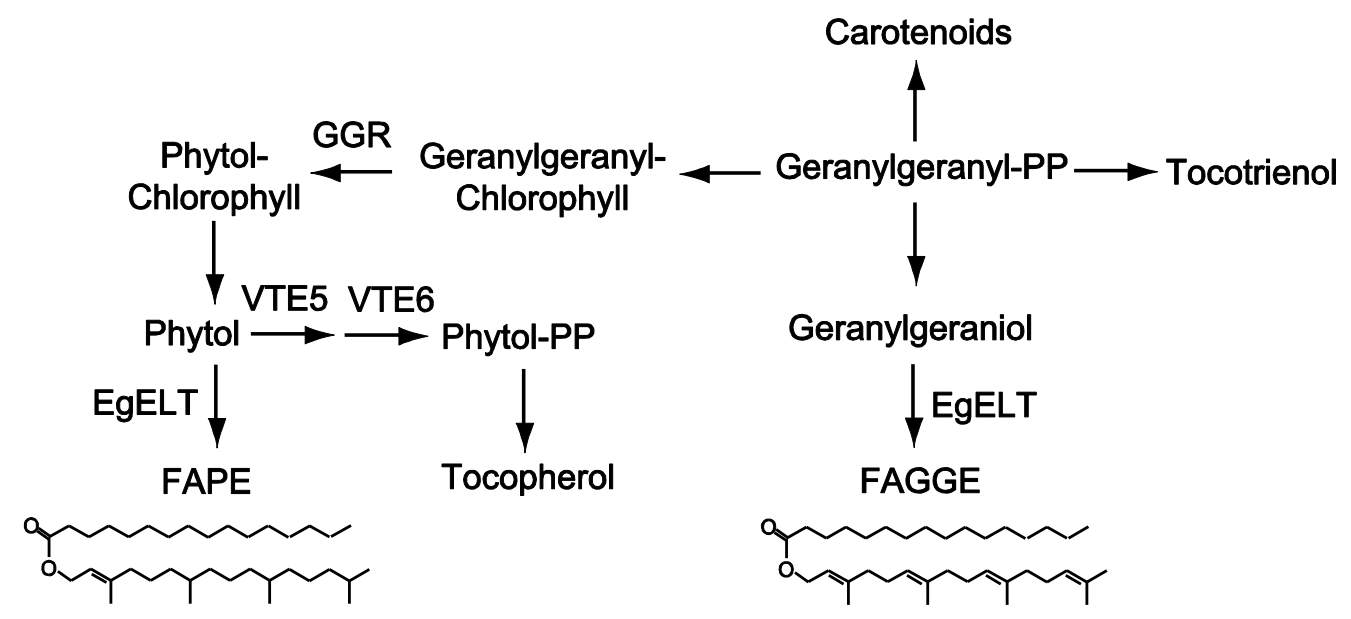

Figure 1 

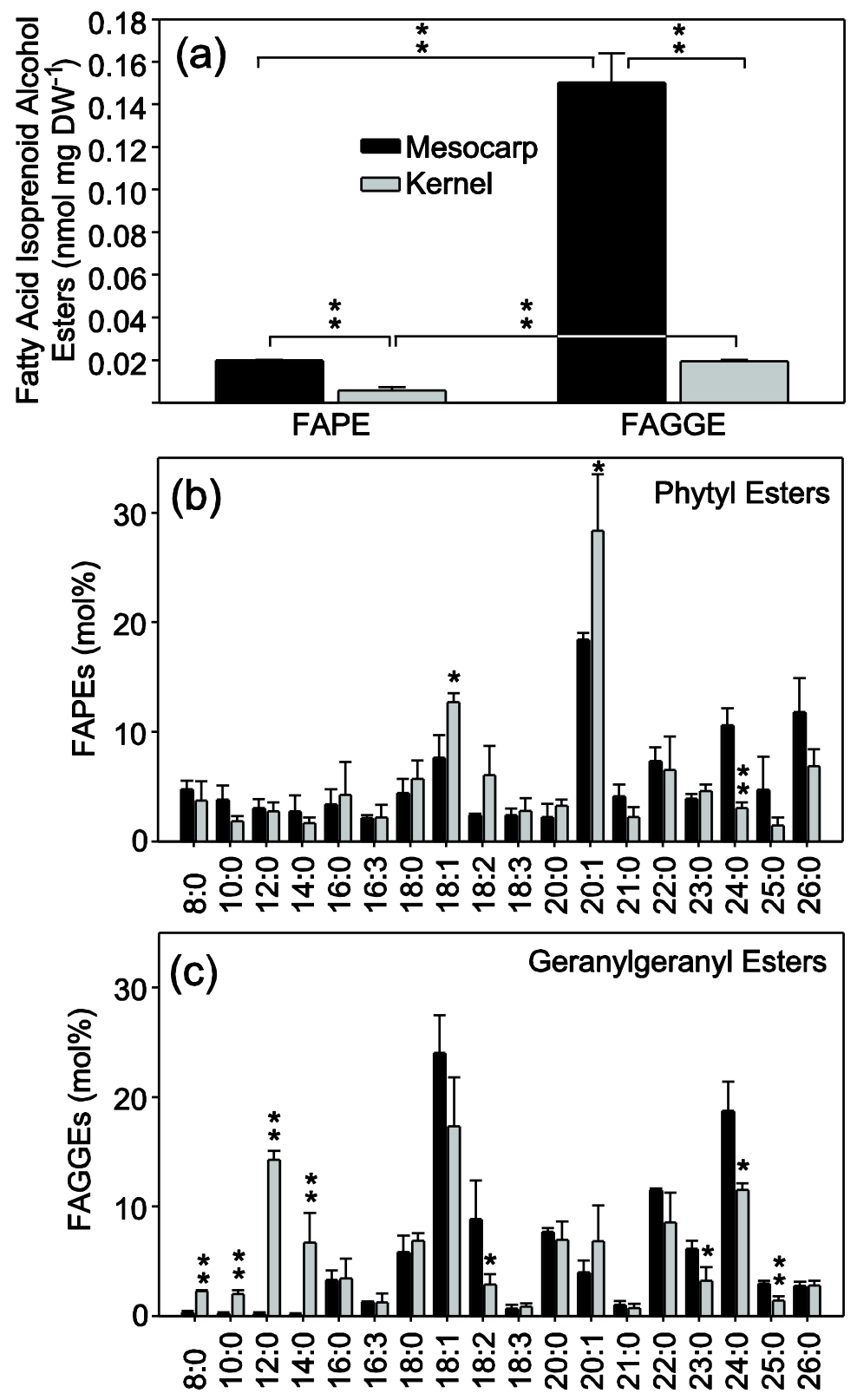

Figure 2 


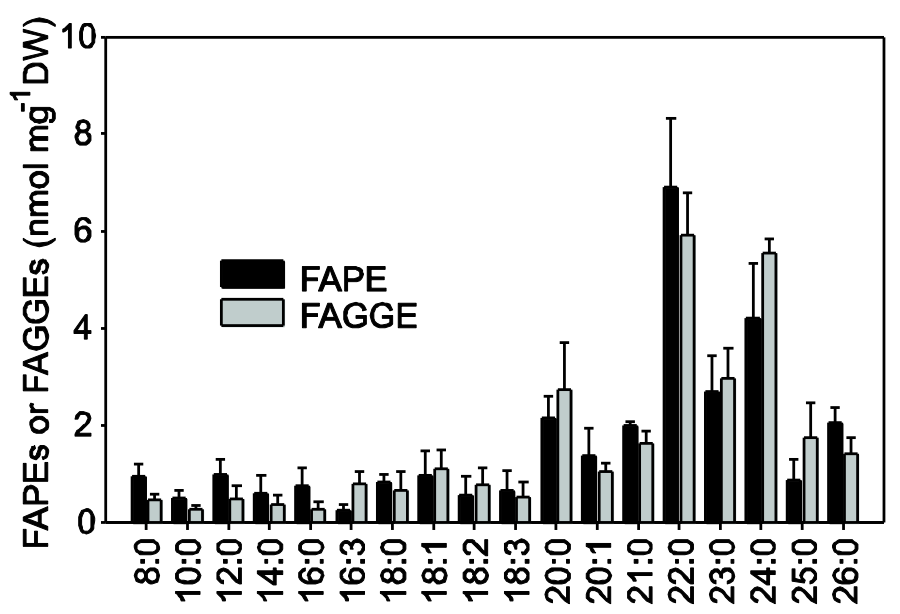

Figure 3 


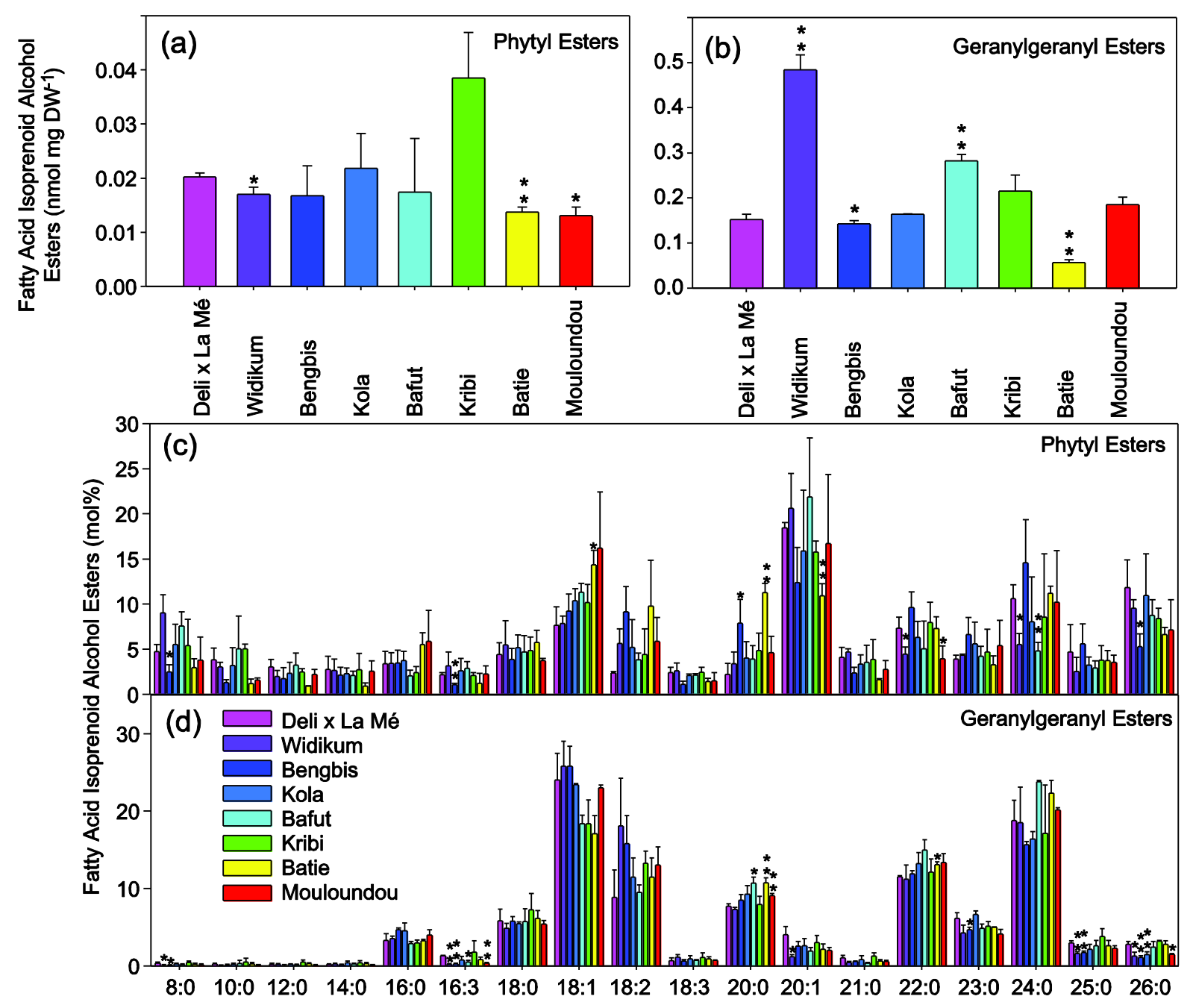

Figure 4 


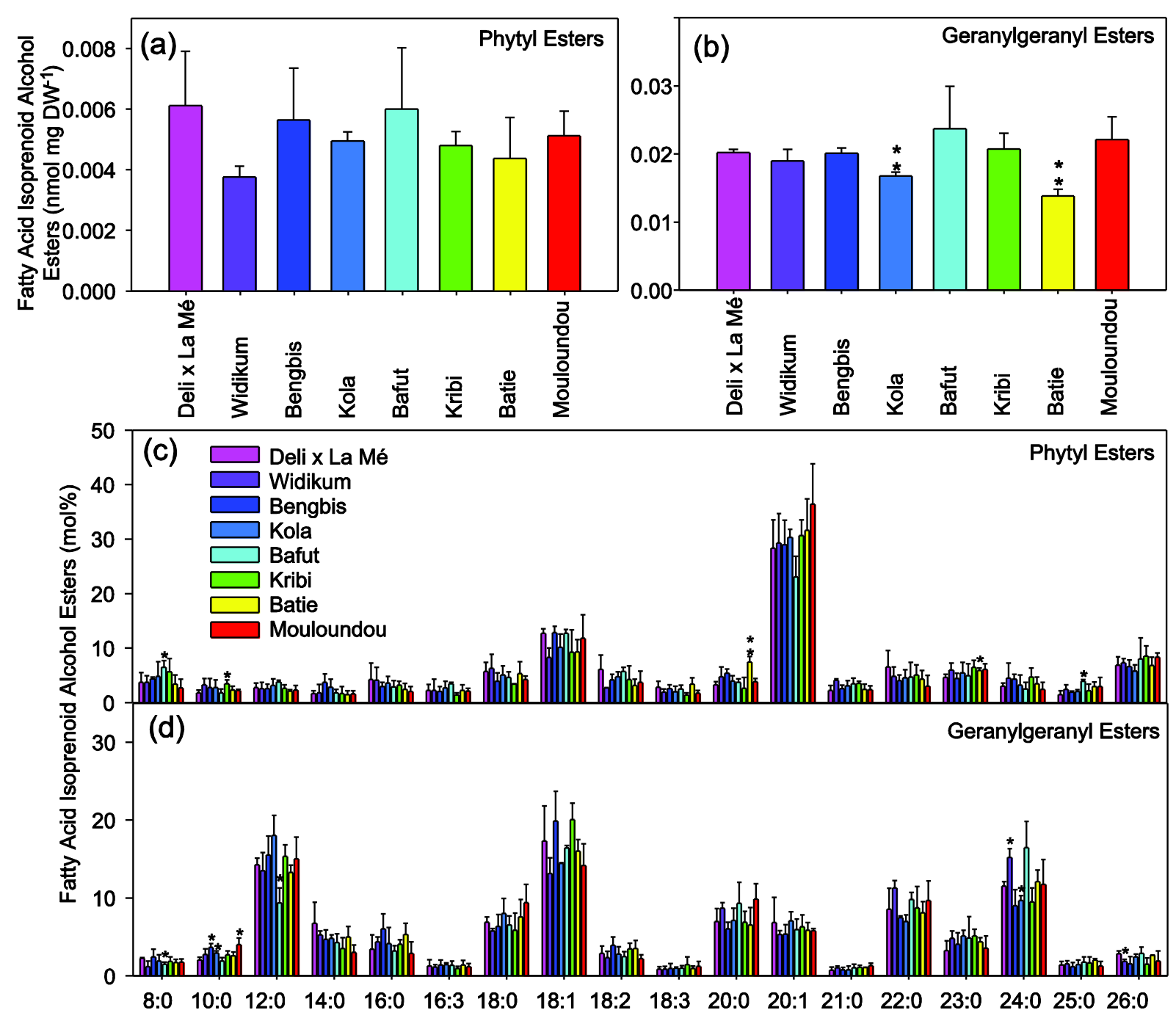

Figure 5 

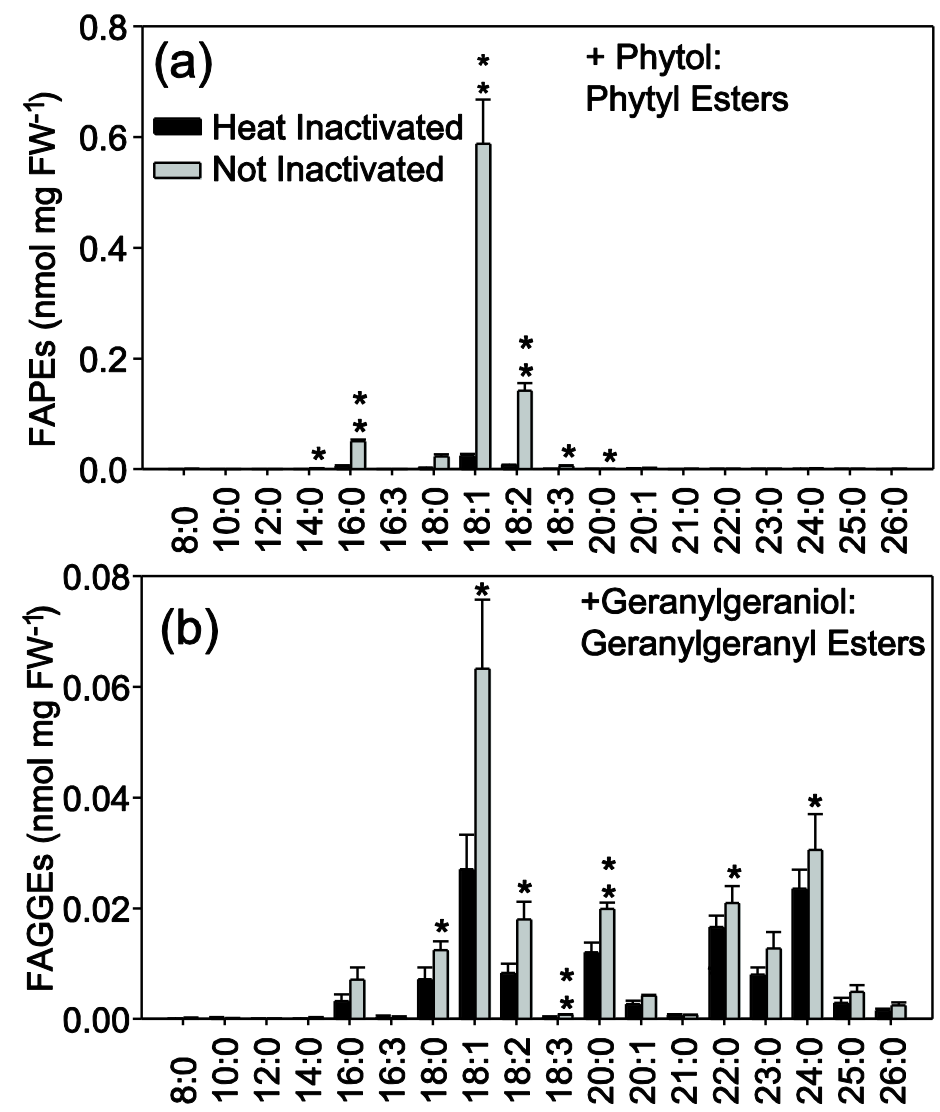

Figure 6 

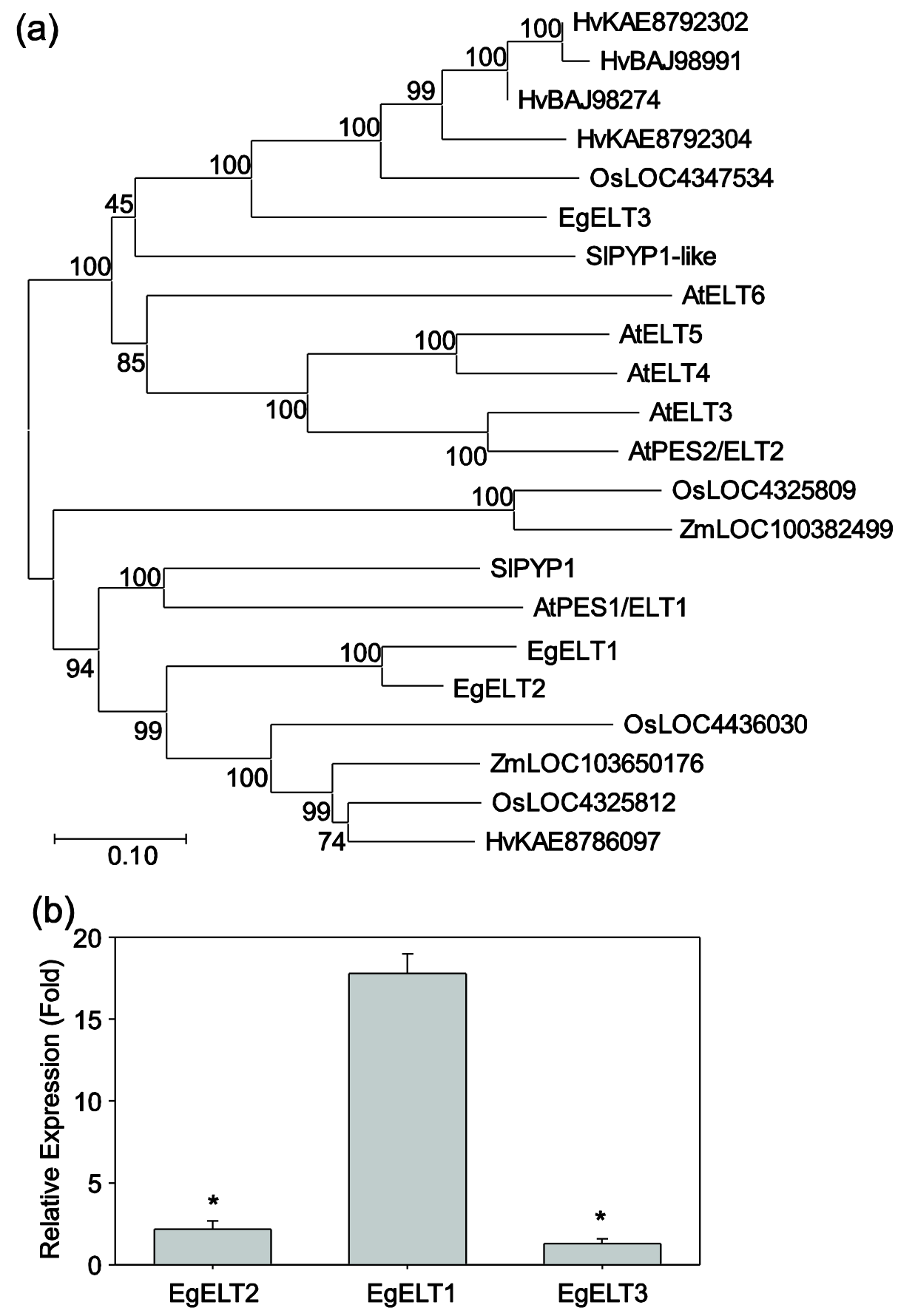

Figure 7 